\title{
Outcome of Management of Diaphragmatic Hernia; Review of Three Year Experience
}

\author{
Ramjee $\operatorname{Prasad}^{1}$, Dinesh kumar barolia ${ }^{1}$, Sunil kumar mehra ${ }^{1}$, Praveen mathur ${ }^{2}$ \\ ${ }^{1}$ Senior Resident, 2 Professor \\ Department Of Paediatric Surgery, Sms Medical College,Jaipur,Rajasthan, India
}

\begin{abstract}
Diaphragmatic hernia (cdh) is a defect in the dome of diaphragm, more often in left and posterolateral that permits the herniation of abdominal contents into the thorax. The lungs hypoplasia, pulmonary hypertension and persistent foetal circulation are important determinant of survival. The incidence is $80 \%$.The aetiology of diaphragmatic hernia is unclear, although $2 \%$ is familial and $15 \%$ of patients have chromosomal abnormalities. Experimental evidence suggests that pulmonary hypoplasia is the primary defect in diaphragmatic hernia.6 failure of separation of the thoracic and abdominal compartments of the body by closure of embryonic pleuroperitoncal canal during eighth week of gestation results congenital diaphragmatic hernia (bochdalek's type). The affected lung is intrinsically abnormal.
\end{abstract}

\section{Introduction}

The lung is obviously hypoplastic on the side of the hernia, but the contralateral one is also affected to a variable extent. All stages of lung development will be affected. Lungs with cdh have underdeveloped airways, abnormal differentiation of type ii pneumocytes, and a reduced number of pulmonary arteries per unit lung volume. Intrapulmonary arteries become excessively muscularized during gestation with thickened adventitia and media. These pulmonary vessels display an abnormal response to vasoactive substances. $7 \mathrm{cdh}$ can be detected during fetal life when screening ultrasonography demonstrates herniation of the intestine and/or the liver into the thorax. Polyhydramnios due to kinking of gastroesophageal junction may help to antenatal diagnosis in some severe cases. 8 respiratory distress within 24 hours of birth should always be suspicious. Classically these infants have scaphoid abdomen and an asymmetric funnel chest. On ascultation of the lungs reveals poor air entry and shift of the mediastinurn to the opposite side. Diagnosis can be established by a plain $\mathrm{x}$ ray of chest with presence of the stomach or loops of bowel within the thoracic cavity along with mediastinal shift away from the side of the lesion.Right sided defects are more difficult to diagnose. In case of confusion, diagnosis can be confirmed by placing a nasogastric tube in the stomach which also gives symptomatic relief to the patient and contrast git series $\mathrm{x}$ ray. Computed tomography of the chest also demonstrates diaphragmatic defect. Routine blood examination, blood grouping and cross matching and frequent blood gas analysis are necessary for management. Extracorporeal membrane oxygenation (ecmo) has been used both as a rescue therapy in those with severe hypoxia after surgical repair and in the stabilisation of infants before and during surgery. Several institutions have reported improvements in survival associated with the use of ecmo, but equally good survival also occurs in centres that do not use ecmo. A recent large uk study, showed that infants who had received ecmo for cdh had a significant mortality in the first year of life, and there was long-term physical and neurodevelopmental morbidity in the majority of survivors.24 surgical repair of cdh was treated as a emergency until the 2014s. However, repair of the defect does not result in an improvement in gas exchange, and thoracic compliance and paco2 tend to deteriorate in the immediate postoperative period. Most centres now delay surgery for at least 24-48 hours after admission, to allow for a period of clinical stabilization and a fall in pulmonary vascular resistance. 24 repair is usually achieved via an abdominal incision with gentle reduction of the abdominal viscera from the thorax. The diaphragmatic defect is either closed by primary repair or, in the case of a large defect, using a plication through standard open procedure or by minimal invasive surgery. 8 postoperatively ventilation should be provided according to the need. Previous concept of routine placement in icu and ett ventilation postoperatively resulted in increasing chance of infection and mortality. Some of the paediatric surgical centre in home and abroad successfully repaired (tension free) the defect primarily without post-operative ventilatory support in icu. 8 so, aim of this reporting was to share our experience that surgical repair of the pre-opearative cardiorespiratory stable patient of cdh with all age group can be done in non-icu setup with hopeful outcome.

\section{Materials And Methods}

This retrospective study was done in jk lon hospital ,Jaipur, over a period of 3 years from march2014 to march 2017. Data were collected from patients' hospital records and analysed for age, sex, clinical features, diagnosis, surgical procedure performed, complications and their outcome. Total of 24 patients with 
diaphragmatic hernia were referred from pediatric practitioners to surgical unit. All patients got resuscitation after admission, nasogastric suction and prophylactic broad-spectrum antibiotics preoperatively and blood was ready for transfusion prior to surgery. Their ages ranged from 1 days to 7 years . All clinically suspected cases were diagnosed preoperatively by abdominal radiology. Only stable patients who are acyanotic with or without traditional nasal tube oxygen inhalation and defect was planned for surgical correction. The hernia was explored per abdominally through left subcostal incision after adequate counseling. Diagnosis was confirmed, defect was identified and isolated. All the herniated abdominal contents were reduced from thoracic to abdominal cavity. Diaphragmatic defects were closed by interrupted prolene stitches. No water-seal drainage or abdominal stretching was done in any case. Oral feeding was started after bowel movement on 4th or 5th pod. Plain $\mathrm{x}$ ray abdomen and thorax was done on 4th or 5th post-operative day to asses lung expansion. Postoperative followup was given at one week and one month after discharge.

\section{Results}

24 cases of diaphragmatic hernia, 19 were posterolateral (bochdalek's type) on left side and 4 were right side and one patient anterior morgagini hernia. Age ranges from 1 days to 7 years (table 1). Among them, 16 were males and 8 were females. Male-female ratio was 2:1. Presenting symptom in all cases were respiratory distress either mild and moderate condition with some also presenting with feature was recurrent abdominal distension and vomiting and presentation was late at 7 years. Despite advances in therapeutic modalities, congenital diaphragmatic hernia $(\mathrm{CDH})$ still accounts for significant neonatal mortality. This study aimed to describe the demographic features, clinical experiences of postnatal care, and differences between non-survivors and survivors with $\mathrm{CDH}$ with all age group. A total of 24- live-born neonates with all age group fulfilled the study criteria; The mean gestational age was $38.8 \pm 1.8$ weeks (range, $35-41$ weeks). Twenty $(85 \%)$ had Bochdalek hernia [19 (83\%) left-sided, 4 (17\%) right-sided], and one (4\%) had right-sided Morgagni hernia. Additional major congenital anomalies were identified in five patients (21\%). The overall mortality was $21 \%$ (5/24); all deaths occurred before and after surgery . Statistically significant differences between survivors and non-survivors were found for right-sided $\mathrm{CDH}$, low 1-minute and 5-minute Apgar scores, and low pH of the first arterial blood gas. Deaths were attributed to severe persistent pulmonary hypertension, unresponsiveness to aggressive resuscitation at birth, and major associated malformations.

outcomes

$\mathrm{CDH}$ have improved with advances in the management of pulmonary hypertension, gentle ventilation techniques, and elective surgery after initial stabilization]. The reported survival rate has improved from $50 \%$ to nearing $85 \%$. The outcome of $\mathrm{CDH}$ depends on the timing of herniation, position of liver, severity of pulmonary hypoplasia, and associated congenital malformations. Antenatal predictors involve markers for severity of lung hypoplasia and pulmonary hypertension. The present study was conducted to assess the outcome at discharge for neonates diagnosed with CDH within 6 hours of life during the period from March 2014 to March 2017 and to find the postnatal factors predicting their survival. The diaphragmatic defect was complete and found on left side in all cases except 4 cases are repair in right side where the defect was covered by a large defect. Associated congenital anomaly was present in 5 cases. Post operatively oxygen was given to all patients through nasal catheter for 24 hours to 72 hours but on 8 baby needed additional assisted ventilation with ett (endotracheal tube) and ambu (artificial manual breathing unit) bag for 24 hours after an transient attack of cyanosis. All babies tolerate feeding well postoperatively after bowel movement. Postoperative x-ray showed good lung expansion, correction of mediatinal shifting and no evidence of any pleural effusion. All study cases $(n=19)$ of cdh survived. So survival rate was $80 \%$.

Table 1 Patient Profile with Outcome

\begin{tabular}{|c|c|c|c|c|c|c|c|c|c|}
\hline $\begin{array}{l}\mathrm{Sr} \\
\text { no }\end{array}$ & $\begin{array}{l}\text { Age/sex } \\
\text { m-male } \\
\text { f-female } \\
\text { d-day }\end{array}$ & $\begin{array}{l}\text { Body } \\
\text { wt.in } \\
\text { gram }\end{array}$ & $\begin{array}{l}\text { Major } \\
\text { sympto } \\
\text { m }\end{array}$ & $\begin{array}{l}\text { Contents herniated } \\
\text { into the chest }\end{array}$ & $\begin{array}{l}\text { Cdh repair } \\
\text { +other }\end{array}$ & $\begin{array}{l}\text { Side of } \\
\text { cdh }\end{array}$ & $\begin{array}{l}\text { Postoper } \\
\text { ventilati } \\
\text { on + } \\
\text { duration }\end{array}$ & $\begin{array}{l}\text { Major } \\
\text { association }\end{array}$ & Outcome \\
\hline 1 & $1 \mathrm{~d} / \mathrm{m}$ & 2700 & Rtd, & $\begin{array}{l}\text { Small bowel, } \\
\text { spleen }\end{array}$ & $\begin{array}{l}\text { Plication/1 } \\
\text { add }\end{array}$ & Left & Nil & Nil & Survived \\
\hline 2 & $5 \mathrm{~d} / \mathrm{m}$ & 3100 & $\begin{array}{l}\text { Vomitin } \\
\mathrm{g}\end{array}$ & $\begin{array}{l}\text { Transverse } \\
\text { colon,omentum }\end{array}$ & $\begin{array}{l}\text { Repair/ } \\
\text { ladds }\end{array}$ & Left & 86 & $\begin{array}{l}\text { Cleft } \\
\text { lip,ASD }\end{array}$ & Expire \\
\hline 3 & $3 \mathrm{~d} / \mathrm{f}$ & 2600 & Rtd & $\begin{array}{l}\text { Small } \\
\text { bowel,stomach }\end{array}$ & Repair & Left & Nil & Nil & Survived \\
\hline 4 & $9 \mathrm{~d} / \mathrm{m}$ & 2600 & $\begin{array}{l}\text { Fever,di } \\
\text { stres }\end{array}$ & $\begin{array}{l}\text { Bowel,pericardiu } \\
\text { m }\end{array}$ & Plication & Left & 48 & $\begin{array}{l}\text { Poly } \\
\text { syndactely, }\end{array}$ & Survived \\
\hline 5 & $1 \mathrm{~d} / \mathrm{m}$ & 2900 & Rtd & $\begin{array}{l}\text { Small bowel, } \\
\text { liver,pericardium }\end{array}$ & $\begin{array}{l}\text { Repair/drai } \\
\mathrm{n}\end{array}$ & Right & 78 & Nil & Expire \\
\hline 6 & $24 \mathrm{~d} / \mathrm{m}$ & 3200 & Vomitin & Liver,gall & Repair/lad & Right & Nil & Nil & Survived \\
\hline
\end{tabular}


Outcome of Management of Diaphragmatic Hernia; Review of Three Year Experience

\begin{tabular}{|c|c|c|c|c|c|c|c|c|c|}
\hline & & & $\mathrm{g}$ & bladder,stomach & $\mathrm{d}$ & & & & \\
\hline 7 & $1 \mathrm{~d} / \mathrm{f}$ & 2400 & $\begin{array}{l}\text { Vomitin } \\
\mathrm{g}\end{array}$ & Colon,stomach & $\begin{array}{l}\text { Repair/drai } \\
\mathrm{n}\end{array}$ & Left & 60 & Nil & Expire \\
\hline 8 & $5 \mathrm{~d} / \mathrm{f}$ & 1700 & Rtd & Small bowel & Repair & Left & 24 & PDA & Survived \\
\hline 9 & $2 \mathrm{~d} / \mathrm{f}$ & 2800 & Rtd, & $\begin{array}{l}\text { Splenic } \\
\text { flexur,bowel }\end{array}$ & Plication & Left & Nil & Nil & Survived \\
\hline 10 & $8 \mathrm{~d} / \mathrm{m}$ & 2100 & $\begin{array}{l}\text { Vomitin } \\
\mathrm{g}\end{array}$ & Small bowel & Repair & Left & Nil & Nil & Survived \\
\hline 11 & $25 \mathrm{~d} / \mathrm{m}$ & 2800 & $\begin{array}{l}\text { Vomitin } \\
\mathrm{g}\end{array}$ & Bowel & Repair & Left & Nil & VSD & Survived \\
\hline 12 & $59 \mathrm{~d} / \mathrm{f}$ & 2900 & $\begin{array}{l}\text { Vomitin } \\
\mathrm{g}\end{array}$ & Whole bowel & Repair & Left & 36 & $\begin{array}{l}\text { Omphaloce } \\
\text { le }\end{array}$ & Survived \\
\hline 13 & $15 \mathrm{~d} / \mathrm{m}$ & 3000 & Rtd & $\begin{array}{l}\text { Liver,stomach,sma } \\
\text { ll bowel }\end{array}$ & $\begin{array}{l}\text { Repair/drai } \\
\mathrm{n}\end{array}$ & $\begin{array}{l}\text { Right } \\
\text { anterior }\end{array}$ & 96 & Nil & Expire \\
\hline 14 & $20 \mathrm{~d} / \mathrm{m}$ & 1800 & Distress & $\begin{array}{l}\text { Small } \\
\text { bowel,stomach }\end{array}$ & $\begin{array}{l}\text { Recurrent } \\
\text { repair }\end{array}$ & Left & Nil & Nil & Survived \\
\hline 15 & $3 \mathrm{~m} / \mathrm{f}$ & 3500 & $\begin{array}{l}\text { Vomitin } \\
\text { g,distres }\end{array}$ & $\begin{array}{l}\text { Whole } \\
\text { bowel,stomach }\end{array}$ & Repair & Left & Nil & Nil & Survived \\
\hline 16 & $6 \mathrm{w} / \mathrm{f}$ & 3200 & $\begin{array}{l}\text { Fever } \\
\text { vomitin } \\
\mathrm{g} \\
\end{array}$ & $\begin{array}{l}\text { Pyothorax,small } \\
\text { bowel }\end{array}$ & $\begin{array}{l}\text { Repar+drai } \\
\mathrm{n}\end{array}$ & Left & Nil & $\begin{array}{l}\text { Hydroceph } \\
\text { alous }\end{array}$ & Survived \\
\hline 17 & $1 \mathrm{~d} / \mathrm{m}$ & 3200 & Distress & Small bowel ,sac & $\begin{array}{l}\text { Repair } \\
\text { /ladds/drai } \\
\mathrm{n}\end{array}$ & Left & 48 & Nil & Expire \\
\hline 18 & $15 \mathrm{~d} / \mathrm{m}$ & 3000 & $\begin{array}{l}\text { Vomitin } \\
\mathrm{g}\end{array}$ & Spleen ,bowel & Repar & Left & Nil & Nil & Survived \\
\hline 19 & $80 \mathrm{~d} / \mathrm{m}$ & 4000 & $\begin{array}{l}\text { Vomitin } \\
\mathrm{g}\end{array}$ & $\begin{array}{l}\text { Stomach,rt lobe } \\
\text { liver,omentum }\end{array}$ & & Left & 7 & Nil & Survived \\
\hline 20 & $6 \mathrm{~m} / \mathrm{m}$ & 5300 & Cough & Small bowel, & Repair & Left & 24 & Nil & Survived \\
\hline 21 & $7 \mathrm{~m} / \mathrm{m}$ & 5800 & Vomi & Stomach,spleen & Repair & Left & Nil & Nil & Survived \\
\hline
\end{tabular}

\begin{tabular}{|c|l|l|l|l|l|l|l|l|l|}
\hline 22 & $8 \mathrm{~m} / \mathrm{m}$ & 6100 & Vomiting & $\begin{array}{l}\text { Spleen } \\
\text { transve. }\end{array}$ & Repair & Left & Nil & Nil & Survived \\
\hline 23 & $\begin{array}{l}10 \mathrm{~m} / \\
\mathrm{m}\end{array}$ & 8000 & Fever, rtd & $\begin{array}{l}\text { Spleen, } \\
\text { omentum }\end{array}$ & Repair/ & Left & Nil & Club foot & Survived \\
\hline 24 & $7 \mathrm{y} / \mathrm{m}$ & $18 \mathrm{~kg}$ & vomiting & $\begin{array}{l}\text { Liver,colon,st } \\
\text { omac }\end{array}$ & Repair & Right & Nil & Cerebral palsy & Survived \\
\hline
\end{tabular}

\section{Discussion}

Posterolateral (bochdalek's type) variety is the commonest type of congenital diaphragmatic hernia. Most of the large series reported that $85-90 \%$ of cdh were bochdalek's type and $80-90 \%$ were in left side. Right sided cdh repair is technically difficult due to presence of liver under right dome. The diaphragmatic defect may be covered by membrane in $10-15 \%$ cases. We also detected a cdh with membrane. Cdh is more frequent among male.

Fig-1. Preoperative plain $x$ ray abdomen and chest showing intrathoracic intestine and mediastinal shifting fig-2. Postoperative show good lung expansion with correction of mediastinal shifting and no evidence of lung collapse or effusion.

Fig-3 cect chest showing anterior right diaphragmatic hernia with bowel loops in right hemithorax with collapse of right lung in preoperative

fig-4. Per-operative view of defect in right dome of diaphragm in neonate

fig-5. Peroperative view of defect in right anterior dome of diaphragm in 7 year

Fig-6 peroperative repair of defect

Fig 1

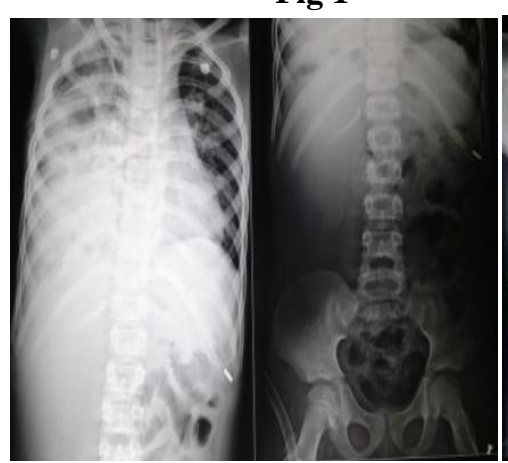

DOI: $10.9790 / 0853-1603056670$ fig 2

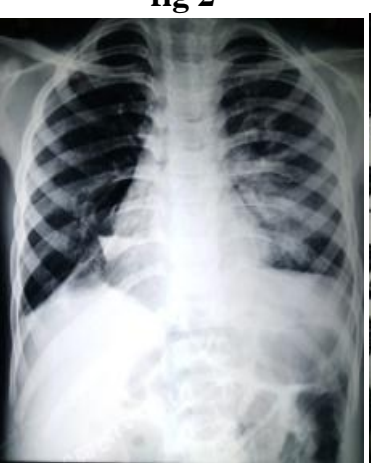

Fig 3

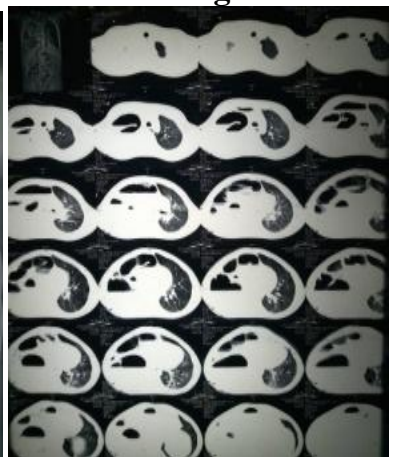

www.iosrjournals.org 


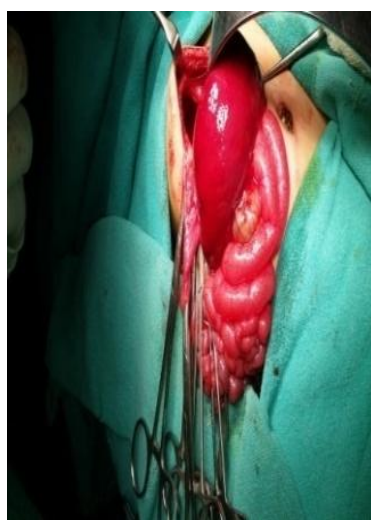

Fig-4

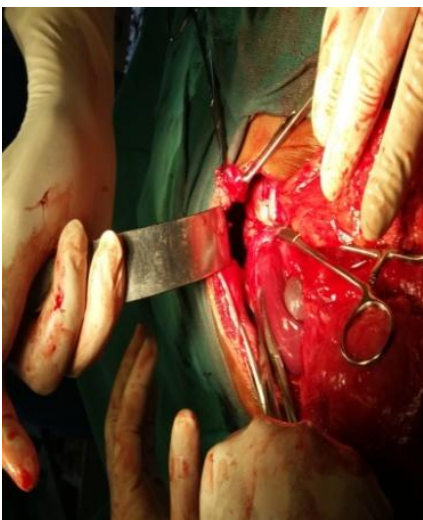

Fig-5

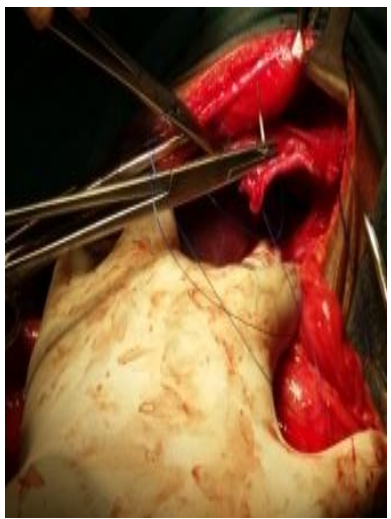

Fig -6

Respiratory distress is the common presenting symptom in neonate. In our study total 15 cases of neonate present out of 24 cases. In our study two children of presented with features of recurrent upper git obstruction with recurrent hernia and acute intestinal obstruction respectively. Diagnosis was confirmed all but one cases by plain $\mathrm{x}$ ray abdomen and thorax (fig 1). Atypical presentation may create diagnostic confusion and needs special investigation. Our late presenting case was also diagnosed by cect chest (fig 3) series. Most important preoperative determinant is respiratory stability. The baby should be acyanotic with or without assisted ventilation. The choice of peroperative approach either thoracic or abdominal depends on surgeon but perabdominal approach is preferable. The diaphragmatic defect (fig- 4-5) may be closed directly . We closed the defect directly by interrupted prolene suture of primary repair of defect in fig-6. Cdh commonly associated with other major anomaly. We found $5(21 \%)$ cases where major anomaly was lipomeningocele, cleft lip and omphalocele majo, anterior septal defect, ventricular septal defect,cerebral palsy, with most of the long series also reported that this association was 15\%-25\%.5-7 post operatively assisted respiration should be provided according to the need. These may vary from oxygen inhalation to artificial ventilation to ecmo. In our series only 8 baby needed overnight artificial respiration with ett and ambu after a transient attack of cyanosis. Oxygen inhalation with traditional nasal tube was given for 24 to 48 hours post operatively in all other cases. Out of 24 patients 16 are boys and 8 are female, with presented there 4 cases were right side and 19 cases are left side one cases anterior right side. Complication was noted in postoperative period and survival was $80 \%$.

\section{Conclusion}

Diaphragmatic hernia is a surgical disease. But it is a medical rather than surgical emergency. Surgical repair of cdh used to be in the past a life-saving emergency. It is presently accepted that it should be undertaken only after cardio-respiratory functions are stable. Good prognosis is expected after repair of the defect on a stable patient even in non-icu setup. Seventy-nine percent of our CDH patients survived to hospital discharge. Resuscitation by a skilled neonatology team to prevent low Apgar scores and low $\mathrm{pH}$, careful evaluation of other anomalies, and overcoming pulmonary hypertension might improve the survival rate. Recognizing unfavorable factors in $\mathrm{CDH}$ may help clinicians manage the critical care of these babies. To conclude, we found a survival of $78 \%$ in isolated $\mathrm{CDH}$ neonates using the standard protocol in management and maximum OI on day 1 is a good outcome for survival.

\section{Reference}

[1]. Hannah king, peter d booker: congenital diaphragmatic hernia in the neonate. Continuing education in anaesthesia, critical care \& pain 2005, 5: pp 171-4 2. Golombek sg:

[2]. the history of congenital diaphragmatic hernia from 1850s to the present. J perinatol 2002, 22: 242-6.

[3]. Gross re. Congenital hernia of the diaphragm. Am j dis child 1946; 71: 579-92.

[4]. Tovar $\mathrm{j}$ a. Congenital diaphragmatic herniaorphanet journal of rare diseases 2012; 7: 1-15

[5]. Hanif a, hasina k, alam mm: congenital diaphragmatic hernia (cdh): profile of 21 cases in dhaka medical college hospital. Bangladesh medical journal 2010, 39: 32-5

[6]. Keijzer r. Liu j. Deimling j, tbboel r. Post m. Dualhit hypothesis explains pulmonary hypoplasia. In the nitrofen model of congenital diaphragmatic hernia. Am j pathol 2000; 156: 1299-306.

[7]. Schnitzer ji: control and regulation of pulmonary hypoplasia associated with congenital diaphragmatic hernia- semin pediatr surg 2004,13: 37-43.

[8]. Sinha ck islam s, patel s, nicolaides k greenough a, davenport m: congenital diaphragmatic hernia: Pandey a, tandon rk, kureel sn, wakhlu a, rawat j. Evaluation of congenital diaphragmatic hernia in a tertiary health center of a developing countrymanagement and survival. Hemia 2008; 12: 189- 92.

[9]. Charlton a, bruce $\mathrm{j}$, davenport $\mathrm{m}$ : timing of surgery in congenital diaphragmatic hernia: low mortality after preoperative stabilization. Anaesthesial 991, 46: 820-3. 11. Sridhar av, nichani s. Late presenting congenital diaphragmatic hernia: emerg med $\mathrm{j}$ 2004; 21: 
[10]. Wenstrom KD, Weiner CP, Hanson JW. A five-year statewide experience with congenital diaphragmatic hernia. Am J Obstet Gynecol 1991;165:838-42.

[11]. 12. Langham MR Jr, Kays DW, Ledbetter DJ, Frentzen B, Sanford LL, Richards DS. Congenital diaphragmatic hernia: epidemiology and outcome. Clin Perinatol 1996;23: 671-88.

[12]. Gross RE. Congenital hernia of the diaphragm. Am J Dis Child 1946;71:579-92.

[13]. Jani J, Gratacos E, Greenough A, et al. Percutaneous fetal endoscopic tracheal occlusion (FETO) for severe left-sided congenital diaphragmatic hernia. Clin Obstet Gynecol 2005;48:910-22.

[14]. Wung JL, Sahni R, Moffitt ST, Lipsitz E, Stolar CJ. Congenital diaphragmatic hernia: survival treated with very delayed surgery, spontaneous respiration, and no chest tube. J Pediatr Surg 1995;30:406-9.

[15]. The Neonatal Inhaled Nitric Oxide Study Group. Inhaled nitric oxide and hypoxic respiratory failure in infants with congenital diaphragmatic hernia. Pediatrics 1997;99: 838-45.

[16]. Reyes C, Chang LK, Waffarn F, Mir H, Warden MJ, Sills J. Delayed repair of congenital diaphragmatic hernia with early highfrequency oscillatory ventilation during preoperative stabilization. J Pediatr Surg 1998;33:1010-6.

[17]. Boloker J, Bateman DA, Wung JT, Solar CJ. Congenital diaphragmatic hernia in 120 infants treated consecutively with permissive hypercapnea/spontaneous respiration/elective repair. J Pediatr Surg 2002;37:357-66.

[18]. Skari H, Bjornland K, Haugen G, Egeland T, Emblem R. Congenital diaphragmatic hernia: a meta-analysis of mortality factors. J Pediatr Surg 2000;35:1187-97.

[19]. Stege G, Fenton A, Jaffray B. Nihilism in the 1990s: the true mortality of congenital diaphragmatic hernia. Pediatrics 2003; $112: 532-5$

[20]. The Congenital Diaphragmatic Hernia Study Group. Defect size determines survival in infants with congenital diaphragmatic hernia. Pediatrics 2007;120:651-7.

[21]. Chou HC, Tang JR, Lai HS, Tsao PN, Yau Tsou KI. Prognostic indicators of survival in infants with congenital diaphragmatic hernia. J Formos Med Assoc 2001;100:173-5.

[22]. Chu SM, Hsieh WS, Lin JN, Yang PH, Fu RH, Kuo CY. Treatment and outcome of congenital diaphragmatic hernia. J Formos Med Assoc 2000;99:844-7. 